\title{
CONTRIBUTOS DA AVALIAÇÃO FORMATIVA PARA ENFRENTAR A COLA NO ENSINO JURÍDICO
}

Natan Figueredo Oliveira*

\section{RESUMO}

Este artigo considera a cola como prática antiética do aluno do ensino superior, que tem impacto no processo de aprendizagem e gera risco para a sua atuação profissional. Com foco no ensino jurídico, analisa a responsabilidade do professor no reconhecimento e redução do problema. Traça uma definição de cola e apresenta as causas que geralmente são apontadas para a sua prática. Propõe a reestruturação da prática avaliativa para desestimular a cola, alterando os ambientes de avaliação tradicional por meio da inserção e priorização de avaliação formativa. Por fim, sugere práticas de avaliação formativa, sem a pretensão de indicar receitas prontas.

Palavras-Chave: Ensino jurídico; Avaliação; Cola; Conduta docente; Avaliação formativa

\section{CONTRIBUTIONS OF THE FORMATIVE EVALUATION TO COMBAT THE PRACTICE OF ACADEMIC FRAUD IN LEGAL TEACHING}

\begin{abstract}
This article adressed the academic fraud as an unethical practice for university law students that impacts the learning process and creates risk for their professional performance. Analyzes the teacher's responsibility in recognizing and reducing the problem. It defines a academic fraud and presents the causes that are usually pointed out for its practice. It proposes the restructuring of the evaluation practice to discourage the academic fraud, replacing the traditional evaluation environments through the insertion and prioritization of formative evaluation. Finally, it suggests formative assessment practices, without pretending to indicate ready-made recipes.
\end{abstract}

KEYWORDS: Legal education; Evaluation; Academic fraud; Teacher conduct; Formative evaluation

\section{INTRODUÇÃO}

$\mathrm{Na}$ véspera da prova de uma das disciplinas que reputa mais difíceis, um aluno universitário considera que a sua dedicação ou tempo disponível não foi suficiente para estudar aquilo que supõe que será objeto de avaliação. Se falhar, provavelmente será reprovado, o que envolve custos para repetir a disciplina, os quais não pode suportar, além do atraso na conclusão do curso e outras implicações para a sua formação profissional. Pensa,

\footnotetext{
* Mestrando em Processo e Direito ao Desenvolvimento pelo Centro Universitário Christus. Especialista em Direito Público pela ESMAPE. Juiz de Direito no Estado da Paraíba. Endereço eletrônico: onatanfigueredo@gmail.com
} 
então, em fazer anotações num pedaço de papel de parte do conteúdo indicado pelo professor para a prova e escondê-lo na roupa. Cônscio de que a conduta é, de algum modo, reprovável, acredita que a sua ação não trará prejuízo para outrem e que lançará mão dos escritos se tais informações forem exigidas, de fato, pela prova e o professor não for capaz de flagrá-lo por ocasião da consulta não permitida.

O professor responsável pela aplicação da prova pode ser daqueles que aperfeiçoam as suas estratégias para detectar artimanhas dos alunos, ou pode ser daqueles que acreditam que o ensino superior, com o público-alvo adulto, pressupõe autonomia e responsabilidade, não comportando a fiscalização neste particular, considerando que atos de tal natureza são problemas de níveis anteriores do ensino.

A situação hipotética apresentada acima ou de modo semelhante pode ter sido experimentada pelo leitor, na condição de estudante ou de professor $^{1}$ e apresenta uma série de fatores que envolvem a complexa malha do processo de ensino e aprendizagem, inclusive sobre metodologias empregadas e, por exemplo, causas para predileção do aluno por uma ou outra disciplina e a exigência de que os alunos apenas memorizem informações.

Para os fins deste estudo, é pertinente limitar-se ao aspecto específico da cola no ensino superior na fase de avaliação, pretendendo enfocar a realidade dos cursos jurídicos no ensino presencial ${ }^{2}$ e cujos profissionais estão sujeitos a avaliações certificatórias mesmo após a graduação.

Nesse cenário, apesar de comumente serem empregados como sinônimos os termos cola, fila ou pesca, neste trabalho será adotada apenas a primeira denominação. Ademais, parte-se do pressuposto de que a prática da cola em avaliação, ainda que possa ser aceita socialmente, constitui um problema educacional a ser resolvido, pois de um modo em geral, e mais especificamente na formação dos profissionais do direito, deve-se primar pela ética nas futuras relações profissionais, sociais e institucionais e com qualidade adequada dos serviços prestados à sociedade.

1 Pesquisas feitas em instituições de ensino superior revelam que cerca de $70 \%$ dos estudantes de cursos superiores já se envolveram em situações de burla à avaliação por meio de cola (VELUDO-DE-OLIVEIRA; AGUIAR; QUEIROZ, BARRICHELLO, 2014; PIMENTA; PIMENTA, 2015, 2016).

2 Embora já tenha sido noticiada a autorização do Ministério da Educação para criação de cursos de direito em modalidade de ensino a distância, trata-se de curso tradicionalmente de ensino presencial, com grande quantidade de instituições de ensino ofertando vagas (mais de 1500 cursos até 2018), o que justifica a abordagem da avaliação feita presencialmente. Nesse sentido: https://www.conjur.com.br/2021-ago-01/mec-aprovagraduacao-direito-100-online-faculdade-recifense. Acesso em $01 \quad$ ago. 2021 e https://www.jota.info/carreira/brasil-tem-mais-de-1-500-cursos-de-direito-mas-so-232-tem-desempenhosatisfatorio-14042020. Acesso em 01 ago.2021. 
Para o enfrentamento do problema não faz sentido incumbir o professor de um papel limitado à fiscalização de provas, por se tratar de uma batalha perdida em sua gênese, tanto por falta de poderes premonitórios sobre o aluno que colará e quais manobras ainda desconhecidas serão empregadas, quanto porque enfrentar o problema por este viés deixa de lado o sentido da existência da avaliação. De outro lado, o professor não deve se recusar a abordar o problema para que não adote postura conivente com a cola.

Assim, propõe-se uma reflexão sobre o processo de avaliação da aprendizagem aliado à necessidade de que o ensino superior não despreze a relevância do componente ético na formação profissional, repensando as formas de avaliação para reduzir as oportunidades e desejos de se trapacear por meio da cola.

A despeito da possível variedade de motivos ou fatores para a prática da cola, pretende-se demonstrar que a identificação do modo tradicional de avaliar o aluno constitui um campo fértil para tal prática reprovável e, com isso, buscar nos estudos sobre avaliação formativa um meio para a redução do problema.

A importância da avaliação é fundamental para o processo educativo e especificamente nos cursos jurídicos, de cunho tradicional, nos quais ainda não se pode alijar por completo a dimensão certificatória da avaliação, notadamente porque os graduandos serão submetidos a exames certificatórios como ENADE, exame da OAB ou concursos públicos para o exercício de suas profissões.

Todavia, ao utilizar-se unicamente de avaliações certificatórias ou somativas, mesmo nos cursos jurídicos, o professor apenas distingue os alunos que atenderam a certos requisitos dos outros que não conseguiram, geralmente, em um único momento avaliativo, sem considerar a evolução do aprendizado. O foco costuma ser a prova, geralmente escrita, e não o processo.

Por isso, propõe-se que também seja incluída na prática docente a avaliação formativa, que acompanha o processo em diferentes momentos e por diversos instrumentos, possibilitando o exame das etapas intermediárias de produção do conhecimento e aprimoramento do desempenho do aluno em diferentes momentos avaliativos.

Por fim, apresentam-se sugestões de avaliações com aplicação de instrumentos distintos da prova única para a aferição da aprendizagem e para que, ao mesmo tempo, os alunos se sintam mais conectados com o que estão aprendendo e menos incentivados a trapacear por meio da cola. 
A metodologia utilizada na elaboração do artigo é descritiva, alinhando-se a uma abordagem qualitativa e o procedimento metodológico considerou artigos científicos e doutrinas específicas sobre a matéria.

\section{A COLA NO ENSINO SUPERIOR E A POSTURA DO PROFESSOR}

A cola consiste na cópia de respostas em exames a partir de troca de informações com colegas, uma olhadinha nas respostas da prova do colega ao lado ou consulta a telefone celular, outro aparelho eletrônico ou a papeizinhos com conteúdo da disciplina avaliada, que são acomodados nas cadeiras ou nos bolsos, mangas e decotes das roupas, nos calçados, em canetas $^{3}$, que podem ser preparados, inclusive, com a aplicação de "técnicas" difundidas em sítios na internet, vídeos e filme ${ }^{4}$.

Em estudo comparativo entre estudantes de direito das regiões nordeste e sudeste do Brasil, foi constatado que dois em cada três estudantes universitários praticam cola nas avaliações no sertão paraibano e que um em cada dois estudantes no interior mineiro também o fazem (PIMENTA; PIMENTA, 2015).

$\mathrm{Na}$ mesma linha, estudo quantitativo descritivo sobre o comportamento de alunos do ensino superior na área de negócios constatou que 69\% dos estudantes de graduação e $73 \%$ dos estudantes de pós-graduação admitem utilizar apontamentos e material de apoio em provas sem consultas e $66 \%$ dos estudantes de graduação e $74 \%$ dos estudantes de pósgraduação disseram permitir que outros alunos copiem suas respostas durante a prova (VELUDO-DE-OLIVEIRA; AGUIAR; QUEIROZ, BARRICHELLO, 2014).

Tais estudos indicam a recorrência da cola, que também é percebida no dia a dia da sala de aula pelo professor e pelos alunos.

Por que os alunos colam? Pode-se dizer que existe uma multiplicidade de fatores que se correlacionam com a prática da cola, envolvendo desde as condições pessoais dos alunos, tais como a dificuldade de conciliar estudos com outras obrigações e afazeres ou mesmo a falta de senso sobre a gravidade da fraude cometida na apropriação do conhecimento, além da

3 Outro conceito, que não será adotado aqui por fugir aos objetivos propostos, considera a cola sinônimo de fraude acadêmica em geral, como burla, cópia integral de trabalhos de terceiros e plágio. (PIMENTA; PIMENTA, 2016).

4 Nesse sentido, Pimenta e Pimenta (2015) citam o filme Quem Não Cola Não Sai da Escola - Cheaters, de Andrew Gurland (EUA, comédia, 2002), e vídeos que na plataforma do youtube ensinam técnicas para colar (em How to cheat on any test, além de um chat explicando como colar), em http://br.answers.yahoo.com/question/index?qid=20060818190643AAenHDI; $\quad$ e $\quad$ ainda em www.perguntascretina.com.br/2008/04/22/como-colar-na-prova-manual-da-cola/. 
banalização da conduta, sensação de impunidade, ou mesmo a postura mais cômoda, no sentido de reduzir o esforço do aluno para obter aprovação. Aliado a isso, pode haver um ambiente propício para a cola, dado pela conivência do professor ao não fiscalizar a aplicação da avaliação ou por falhar na elaboração do plano de ensino e do próprio instrumento de avaliação.

Ademais, a frequência de comportamentos fraudulentos ou antiéticos em outros âmbitos da sociedade, como nos esportes, negócios e na política também refletem dentro da sala de aula e comprometem o sistema de avaliação da aprendizagem (CALLAHAN, 2004), razão pela qual não se despreza os aspectos sociais e culturais que envolvem o comportamento dos alunos.

Nesse sentido e com olhos para a realidade cultural do Brasil, correlaciona-se a cola com o "jeitinho brasileiro", aquele comportamento que envolve um jogo de cintura para flexibilizar regulamentações (BARBOSA, L., 2005), de modo que a cola poderia ser tratada como mais uma forma de resolver uma dificuldade, por meio de atalhos e percursos menos árduos.

Independentemente da causa ser social, cultural, pessoal, deve-se considerar que isso desvaloriza o conhecimento, permitindo a simulação do aprendizado e a obtenção de vantagem a partir de comportamento antiético e, ainda, que a falta de abordagem séria do tema, ou feita de forma jocosa, acaba por tornar a cola algo banal aos olhos de quem pratica (VELUDO-DE-OLIVEIRA; AGUIAR; QUEIROZ, BARRICHELLO, 2014).

Há quem aponte grave responsabilidade do professor e dos aspectos do ambiente universitário para o por quê da cola, na medida em que não se instiga o pensamento crítico dos alunos, excede-se na quantidade de aulas expositivas e com foco na memorização das falas do professor ${ }^{5}$, falha-se na capacidade de orientar as pesquisas dos alunos e de elaborar adequadamente o plano de ensino (BARBOSA, E., 2013), havendo uma necessidade de reformular as práticas educacionais.

Assim, é possível dizer que o trabalho do professor através do tipo de aula planejada e ministrada e da avaliação por ele adotada pode contribuir para que o ambiente seja propício à prática da cola, sem, evidentemente, desprezar o componente ético envolvido na conduta daqueles que colam.

5 "Apesar de a memorização ser uma habilidade que o homem pode desenvolver, quando se trata de educação essa habilidade não resolve tudo, porque apenas condiciona" (BARBOSA, E., 2013). 
Um estudo realizado para a UNESCO indicou que o aumento da fraude acadêmica ocorre em países desenvolvidos e em desenvolvimento, constituindo uma ameaça ao funcionamento eficiente das instituições e à confiança que a sociedade deposita nelas, advertindo

que os profissionais da área da educação estavam desconsiderando a gravidade do problema, dedicando-lhe pouca atenção - apesar de haver notórios motivos para lhe dar prioridade. Além disso, cumpre ressaltar que aceitar a falta de integridade e comportamento antiético, nas relações institucionais, sociais e comerciais, contraria os verdadeiros propósitos da educação: desenvolver a cidadania e o respeito às leis, aos direitos humanos e à equidade (PIMENTA, DOMINGUES; VIEIRA, 2019, p. $6)$.

Se o objeto da avaliação é consubstanciado numa prova para aprovar ou reprovar o aluno, parece intuitivo que a cola possibilita a certificação do desempenho de aluno com lapso de aprendizagem, o que pode comprometer a vida e a segurança de outras pessoas, já que é crível a possibilidade de reprodução da prática da fraude universitária na vida profissional. Logo, na formação dos alunos, professores e instituições de ensino precisam garantir o cuidado com outras dimensões do desenvolvimento humano, como a formação ética para prevenir atitudes fraudulentas (PIMENTA; DOMINGUES; VIEIRA, 2019).

A preocupação se justifica porque aqueles que completam os estudos são certificados para ingressar no mercado de trabalho como profissionais capazes de desempenhar funções com responsabilidade. O cliente do advogado, contratante leigo, não deve ser obrigado a checar a competência do profissional contratado nem possui meios para fazê-lo, de modo que a confiança é uma das bases da negociação e decorre de um sistema que legitima a atuação do profissional formado (PIMENTA;PIMENTA, 2016). Porém, se a formação decorre de aprovações fundadas em fraudes nas avaliações, é evidente que a instituição de ensino e o professor falharam com o aluno e, em especial, com a sociedade.

Então, se é possível aceitar a existência de um sério desdobramento da prática da cola universitária na formação e na vida profissional, não se deseja chancelar a postura do professor que não considera a cola um problema a ser enfrentado, sendo injustificado o argumento de que o ensino superior tem um público-alvo adulto, que pressupõe autonomia e responsabilidade, e que os atos de tal natureza são problemas de níveis anteriores do ensino.

Crê-se que o leitor não contrataria os serviços de um advogado para atender a uma relevante demanda sua ou para fazer uma parceria se tivesse ciência de que ele optou por colar como atalho para ser aprovado, pois tal circunstância pode tornar o advogado um profissional de competência duvidosa. 
Como resolver o problema do deficit de aprendizagem ou de posturas antiéticas do profissional resultantes da prática da cola enquanto estudante? A mera possibilidade de multar o advogado trapaceiro por litigância de má-fé no processo em que atua resolveria o problema? A possibilidade de aplicar sanções disciplinares pelo conselho de classe ou pelas corregedorias resolveria o problema de condutas profissionais fraudulentas? A substituição do profissional na vaga de emprego resolveria o problema? Tais cogitações consideram a repressão sem pensar na origem do problema que não pode ser desprezada sob pena de sua perpetuação, ou seja, o foco merece estar na formação.

“O papel das faculdades e universidades, que certificam os estudantes, não é apenas desenvolver as habilidades acadêmicas e expandir conhecimento, mas também discutir valores, transmitir padrões de conduta e aprimorar o caráter" (COSTA; PIMENTA, 2015, p. 112). Assim, não é razoável negar a dimensão educativa do trabalho do professor, sendo preciso criar situações que facilitem a tomada de consciência e construção de valores, o que não pode ser limitado a uma grade horária, sem passar pelo conjunto do currículo e trabalho de competências específicas como desenvolvimento de senso de responsabilidade, solidariedade e entendimento de justiça (PERRENOUD, 2000).

Apesar da tomada de consciência da necessidade de reestruturação das práticas
educativas, por parte das direções das instituições de ensino, de forma a desconstruir
o marco da "cola" no ensino superior, o engajamento de alunos e professores no
desenvolvimento e aplicação de estratégias estruturadas e direcionadas para
desincentivar a "cola" pode ser o começo dessa desconstrução (BARBOSA, E.
2013).

Nesse contexto, de necessidade de restruturação das práticas educativas para desestimular a prática da cola, com uma ação proativa em vários níveis do sistema de ensino, destacam-se as condições em que se realiza a avaliação de conhecimentos e competências no ambiente universitário, em especial nos cursos de direito, cujo ensino tradicional costuma não ser acompanhado de práticas e metodologias participativas, resultando em avaliações igualmente tradicionais e propícias à cola.

Isso porque a avaliação costuma ocorrer em um único momento que é a chance de aprovação do aluno e, assim, valoriza-se mais a nota do que o conhecimento, gerando o receio do aluno de ser reprovado, circunstância que pode ser estimulante para a adesão à cola com o fim de afastar o risco da reprovação. 
Neste ponto é pertinente propor repensar a avaliação como meio eficaz de aferição da aprendizagem e também como uma forma para que os alunos se sintam mais conectados com aquilo que estão estudando e, com isso, desincentivados a trapacear por meio da cola.

\section{A AVALIAÇÃO FORMATIVA COMO MEIO DE DESINCENTIVAR A COLA}

Avaliar consiste em julgar a qualidade de alguma coisa e constitui parte do cotidiano de todos, desde o julgamento sobre a qualidade da comida do almoço, sobre as expressões das pessoas com quem se dialoga, sobre a qualidade da estrada em que se trafega etc. No contexto educacional, avaliação pode possuir vários significados, referindo-se à coleta, revisão e uso sistemático de informações sobre programas educacionais, sobre funcionamento das instituições em conformidade com os órgãos de regulação, sobre adequação dos plano de ensino à matriz curricular etc.

Especificamente quanto ao ensino e aprendizagem a avaliação constitui um processo específico que compreende o momento de "dizer o valor, determinar o que é precioso, relevante" (GHIRARDI, 2012, p. 64), de modo a orientar as expectativas dos alunos e a forma como apreendem e respondem à proposta do curso.

Não há dúvida de que ensino e aprendizagem continuam sendo elementos centrais do processo de educação, inclusive no ensino superior, e mesmo que seja tentador fundir os conceitos, não é porque o ensino está ocorrendo que a aprendizagem também esteja. Por isso, a avaliação aparece como um importante elemento de compreensão da aprendizagem do aluno e da forma de ensinar do professor.

Quando se fala em avaliação tem-se um processo complexo que envolve atores e múltiplas variáveis, sendo equivocado assumir que apenas o aluno é avaliado e que o objeto da avaliação seja apenas o que o aluno conseguiu amealhar (GHIRARDI, 2012). Afinal, a avaliação da aprendizagem se destaca em momentos diferentes do ensino-aprendizagem: o diagnóstico, no início do processo; a formativa, enquanto em andamento, e a somativa no final.

A perspectiva tradicional e mais comum compreende a avaliação na sua dimensão certificatória ou somativa, através da qual se considera o acúmulo do conhecimento para ser aferido, em geral, em um único momento, com foco no produto, que na maioria das vezes consiste em uma prova escrita, à qual será atribuída uma nota ou um conceito. 
Sob tal ótica não há análise da evolução ou involução da aprendizagem nem da contribuição do professor, nem sobre o curso. O foco é o grau de resposta do aluno, limitando-se o professor a certificar, formalmente, o resultado obtido (GHIRARDI, 2012).

Deveras, a avaliação classificatória não atua como catalisadora da aprendizagem nem promove investimento em tempo ou recursos para avaliar. Ela condensa a qualidade e quantidade de aprendizagem numa ocasião e a mede, pesa e, talvez o mais importante, restringe o resultado a um único número ou letra avaliativa, dependendo do sistema. Esse número é a medida do desempenho para conhecimento, compreensão e habilidades (FRIEDLAND, 2017).

Nos cursos jurídicos essa perspectiva parece fazer eco nos processos seletivos pelos quais se sujeitarão os alunos para a conclusão e após a conclusão do curso, já que os concluintes estão sujeitos ao $\mathrm{ENADE}^{6}$, ao exame da $\mathrm{OAB}$ e também aos concursos públicos para as carreiras jurídicas, sendo todos estes exemplos espécies de avaliações certificatórias. Porém, ainda que se considere a importância de tal perspectiva à luz das exigências externas do ensino, limitar a avaliação nos cursos de direito à certificação, empobrece a sua potencialidade educativa, pois não possibilita que o aluno evolua a partir da análise e reflexão do seu desempenho no processo de aprendizagem (GHIRARDI, 2012).

Para superar esta limitação, defende-se a avaliação formativa, que permite ao aluno perceber em que estágio se encontra na progressão do curso, refletindo sobre o modo como respondeu ao desafio apresentado pelo professor-avaliador. A avaliação formativa tem por pressuposto a existência de retornos avaliativos para o aluno e momentos, instrumentos e modelos avaliativos diversos (GHIRARDI, 2012).

Em cotejo, a perspectiva formativa, diferentemente da certificatória ou somativa, possibilita a retomada do aperfeiçoamento, dando chance ao aluno de aprimorar o aprendizado e superar as suas dificuldades e lacunas, por meio da articulação de habilidades e capacidades que são trabalhadas e avaliadas como competência geral para construir o saber e mediante uma pluralidade de instrumentos empregados em tempos distintos do curso. Assim,

6 O ENADE - Exame Nacional de Desempenho dos Estudantes é aplicado pelo governo federal para avaliar "o rendimento dos concluintes dos cursos de graduação em relação aos conteúdos programáticos previstos nas diretrizes curriculares dos cursos, o desenvolvimento de competências e habilidades necessárias ao aprofundamento da formação geral e profissional, e o nível de atualização dos estudantes com relação à realidade brasileira e mundial", como indicado pelo Instituto Nacional de Estudos e Pesquisas Educacionais Anísio Teixeira, autarquia federal vinculada ao Ministério da Educação. Disponível em https://www.gov.br/inep/ptbr/areas-de-atuacao/avaliacao-e-exames-educacionais/enade. Acesso em 26 dez. 2020. 
em vez de apenas uma prova escrita, a avaliação compreende debates, participação em aula, role-plays, seminários, simulações, diários etc (GHIRARDI, 2012).

A distinção apresentada parece justificar porque o paradigma tradicional, ao contrário da proposta formativa, constitui um campo propício para a prática da cola. Afinal, está centrado em aulas expositivas, protagonismo do professor, avaliações que costumam limitarse a provas escritas no final do curso e com o propósito de que os alunos memorizem informações (CENTRO DE ENSINO E PESQUISA EM INOVAÇÃO, 2018). Basta imaginar que alguns alunos não têm ideia de como estão se saindo até o exame final, quando, então, parece ser tarde demais para fazer algo a respeito ou quando aquela é a sua única chance de aprovação.

O desestímulo à cola pode vir da transformação desse momento avaliativo decisivo e fatal em um processo de avaliação continuada concomitantemente ao ensino e aprendizagem. Nesse caso, a burla pensada ou preparada para comunicação com colegas ou consultas indevidas perde sentido se a atividade que estiver sendo avaliada considerar, para além de memorização, outras aptidões relacionadas com a apropriação do conhecimento e a sua aplicação prática.

Uma compreensão mais ampla do desempenho do aluno, que se obtém através de avaliações contínuas, possibilita ao professor e ao aluno visualizarem o desenvolvimento e o progresso do ensino-aprendizagem. Isso tem o condão de expandir a motivação do aluno a descobrir as suas habilidades, inclusive sobre se tornarem profissionais éticos e que, formados, saberão, por exemplo, usar precedentes, leis, a Constituição, trabalhar com processos e investigações, liderar equipes, promover negociações etc (FRIEDLAND, 2017).

As notas, embora relevantes, são incapazes de capturar as complexas interações entre alunos e realizações acadêmicas e aqueles aspectos que não são testados numa avaliação certificatória e podem ser revelados pela avaliação formativa como ética, atitude, esforço, pontualidade, trabalho em equipe e outros tão importantes para o dia a dia do profissional do direito.

Além disso, as vantagens da avaliação formativa podem até aliviar o desconforto que existe entre avaliados e avaliadores no processo. Vista pelos alunos, a avaliação

é o obstáculo que eles precisam superar para serem aprovados e alcançarem os créditos daquela disciplina - ao menos na regulação educacional atual. Cada instituição estabelece seus critérios de aprovação, mas dificilmente eles fogem da necessidade de uma nota mínima, que indica, inclusive, o grau de rigidez e exigência do curso. (KLAFKE; FEFERBAUM, 2020, p. 263-264). 
Para lidar com as dificuldades e desconforto relacionados com a avaliação, há alunos que aprendem superficialmente para obter a média e aqueles que fraudam o processo por meio da cola, comprometendo a função da avaliação e a qualidade da educação (PIMENTA; DOMINGUES; VIEIRA, 2019).

Enfim, virar a chave para abrir a porta de uma nova forma de pensar e aplicar a avaliação pode minorar as dificuldades que se apresentam para aluno e para o professor no momento da avaliação e, ao mesmo tempo, promover uma conexão do aluno com aquilo que está aprendendo, diminuindo a margem e a oportunidade da cola.

Algumas advertências precisam ser feitas aqui. Primeiro, não se está defendendo a abolição da prova ou do momento de certificação do conhecimento técnico dos estudantes de direito que, fora dos bancos universitários, serão submetidos a exames de tal natureza, mas sim propondo a conciliação das múltiplas perspectivas avaliatórias, permitindo utilizar a avaliação para tratar, inclusive, de dilemas éticos. Segundo, não se ignora que a adoção da avaliação formativa pode depender de diretrizes da instituição de ensino ou de questões burocráticas impostas ao professor, o que limita a sua atuação em cada caso ou demanda um esforço maior de sua parte para alterar o cenário que comumente se repete.

Apresenta-se, assim, a adição da avaliação formativa nos cursos de direito como um dos meios a ser considerado para a correção do desvio ético do aluno que cola nas avaliações, contudo, sem olvidar da existência de outros meios de fraude acadêmica como plágio, compras de trabalho feitos por terceiros, etc. que não comportam exame neste estudo e que continuarão a demandar a atenção dos atores do processo educativo.

Com essas considerações, reforça-se a possibilidade de que a avaliação formativa possa apresentar novos contornos para o aluno acostumado ou tendente à cola.

Repensando a avaliação, ela poderá ser vista mais do que um meio para recompensar e motivar o aluno, servirá para indicar o que eles sabem e o que não sabem; mais do que punir ou certificar e classificar ou comparar os alunos, na conhecida curva de Gauss ${ }^{7}$, servirá para

\footnotetext{
7 O termo é derivado do nome do matemático alemão Carl Friedrich Gauss e também chamada "curva em sino", em razão do seu formato. De acordo com Klafke e Ferfebaum (2020, p. 264), chama-se curva de Gauss a representação gráfica da distribuição dos alunos segundo grupos de desempenho, que normalmente está na cabeça de vários docentes quando eles avaliam comparativamente os alunos. O problema dessa comparação é tomar o parâmetro dos melhores alunos como referências para os demais. Quando o julgamento do desempenho dos estudantes se torna um exercício de identificar o melhor de todos e classificar os demais a partir dele, passa a ignorar a trajetória de evolução que uma pessoa pode ter tido ao longo do período letivo e, pior, desconsidera o que pode ter atingido o desempenho mínimo que se esperava para aquele objetivo de aprendizagem.
} 
diagnosticar, capacitar e melhorar a qualidade de aprendizagem, valorizando o comportamento ético.

\section{SUGESTÕES PRÁTICAS PARA AVALIAÇÃO FORMATIVA NO ENSINO JURÍDICO}

Sem a pretensão de apresentar simplificações inúteis e fórmulas mágicas ou receitas prontas, que não se conformam com a complexa realidade da avaliação, indicar-se-á a seguir algumas sugestões encontradas na literatura de práticas de avaliação como processo e que sirvam para inspiração, reflexão e início da construção do cenário desejado na proposta apresentada acima.

Antes, porém, rememore-se que qualquer instrumento ou modelo de avaliação aplicado pelo professor precisa ser adequado ao programa de ensino e ao seu propósito. De todo modo, em qualquer deles a avaliação deverá estar baseada em, pelo menos, três critérios: validade, confiabilidade e eficiência (FRIEDLAND, 2017).

A validade de conteúdo significa que a avaliação deve testar aquilo que se pretende medir. Por exemplo, um termômetro deve ser usado para medir a temperatura, não a velocidade (FRIEDLAND, 2017). Logo, no curso de direito, um teste é válido se medir o que o professor objetivava que os alunos aprendessem: elaborar um contrato, atender um cliente, promover o julgamento de um litígio, redigir um recurso, acompanhar uma investigação, saber como se constitui uma servidão, pesquisar os fundamentos de determinado instituto etc.

Assim, quanto maior o número de itens em um tópico e quanto maior a variedade de questões a serem trabalhadas é mais provável que o teste avaliará validamente a competência no que diz respeito às habilidades, conhecimento ou aplicação desse conhecimento que foi projetado. É o que acontece, ilustrativamente, quando um professor de direito civil ministra aula sobre uma disputa envolvendo responsabilidade civil contratual e, de acordo com os objetivos da aprendizagem, adota um instrumento capaz de avaliar o que foi aprendido sobre as teorias, a lei, as classificações doutrinárias, a aplicação prática das regras estudadas, os instrumentos jurídicos, como a jurisprudência foi construída, a possibilidade de solução extrajudicial da disputa, etc. Destarte, quanto mais habilidades, conhecimento e aplicação desse conhecimento forem projetados para serem medidos, mais válida será a avaliação.

O segundo critério é a confiabilidade, que requer que a avaliação seja medida de forma consistente e com a proteção de tratamento igualitário, de modo que respostas 
semelhantes devem ser pontuadas semelhantemente. Se houver variação de avaliação de respostas próximas ou semelhantes, o exame não será confiável. A confiabilidade, portanto, concentra-se na metodologia da avaliação usada para pontuar (FRIEDLAND, 2017). A confiabilidade está relacionada com a forma como professor pode justificar os seus julgamentos.

Neste particular, parece que a elaboração de uma matriz de avaliação pode ajudar na visualização das competências desenvolvidas e garantir o alinhamento da competência ou comportamento e a nota ou conceito atribuído.

Organizar critérios e aspectos a serem avaliados em um quadro ou matriz possibilita
uma visão geral da maneira como a avaliação foi construída, além do encadeamento
item por item viabilizando ajustes ao longo da jornada.
Uma matriz de avaliação deve conter os objetivos de aprendizagem (o que se deseja
que os estudantes aprendam), aos quais devem ser vinculados os indicadores de
desempenho (o que será avaliado), critérios de avaliação (como será avaliado) e os
instrumentos para aferição do desempenho (como será aferido).
(...)
E mais: é essencial que os alunos sejam de fato avaliados pelos critérios
estabelecidos no início. Tais parâmetros não apenas ajudarão os estudantes a se
programar e criar uma estratégia de aprendizagem, como lhes permitirão
compreender como o docente chegou às notas finais, questionar algum cálculo ou
aspecto qualitativo. Também são uma segurança para o professor no momento de
justificar seus julgamentos (KLAFKE; FEFERBAUM, 2020, p. 264).

O terceiro critério é a eficiência, significando que a avaliação deve ser viável, executável, não podendo, por exemplo, ser aplicada uma avaliação longa o suficiente para que, em vez de medir o conhecimento e sua aplicação, comece a medir a resistência do aluno. De igual modo, se a avaliação faz referência a lugares, culturas, idiomas com os quais o aluno não tem familiaridade nem tinha como aprender suficientemente, isso produzirá resultados distorcidos e, portanto, a avaliação será ineficaz e injusta (FRIEDLAND, 2017). Seria o caso, por exemplo, de numa disciplina de direito processual civil serem aplicados exames de fluência em latim e submissão dos alunos à elaboração de uma petição integralmente em latim, a despeito de a língua portuguesa ser o idioma oficial brasileiro (art. 13 da Constituição da República) e obrigatório o uso do vernáculo nos atos e termos do processo (art. 156 do Código de Processo Civil).

Desse modo, partindo-se da ideia de que qualquer avaliação deve ser válida, confiável e eficaz e que isso tem estreita relação com a coerência da avaliação, com os propósitos do curso e com os objetivos da aprendizagem, é que se conclui que, por princípio, tais critérios também devem ser empregados nos modelos e instrumentos de avaliações formativas. 
Feitas estas considerações, é importante que na dimensão formativa, assim como em qualquer outra, o aluno saiba antecipadamente quais são os instrumentos, modalidades e momentos avaliativos. Isso implica na necessidade de que o professor os pense e os planeje com antecedência e indique os objetivos da aprendizagem já no início do curso, assegurando a ciência do aluno sobre o que efetivamente será avaliado, tanto para obter uma nota ou conceito quanto para diagnosticar a qualidade da sua aprendizagem.

Em paralelo, é importante que o professor seja capaz de dar feedbacks de desempenho que encorajem os alunos a se envolver nas atividades, ver o que funcionou ou não e possa desenvolver um plano de melhoria, esforçando-se mais ou corrigindo comportamentos. O retorno deve responder a bons desempenhos levando os alunos a se desafiarem mais e os maus desempenhos a se recuperarem (KLAFKE; FEFERBAUM, 2020).

Para dar feedbacks o professor deve fazê-lo de forma construtiva, frequente, amável, com vistas ao futuro, propiciando um diagnóstico para que tenha mais chances de não ser considerado uma crítica vazia (KLAFKE; FEFERBAUM, 2020). O passo a passo para oferecer um feedback construtivo considera:

1. Refletir sobre o desempenho dos alunos.

2. Elencar fatos que aconteceram (revisitar mentalmente ou consultar anotações).

3. Listar comportamentos que podem ajudar na melhoria dos resultados.

4. Escolher um momento para oferecer feedback.

5. Dar feedback, escutar os alunos e dialogar.

6. Encerrar com possibilidades de ação.

Para que isso ocorra, é fundamental um clima de confiança e respeito entre todos os participantes. Isso, porém, não é dado e deve ser construído pelo professor com os alunos (KLAFKE; FEFERBAUM, 2020, p. 281-282).

Assim, o ciclo de feedback envolvido na avaliação formativa servirá também para que, idealmente, o professor possa ajustar o ensino dentro do próprio curso e não apenas da próxima vez que for ministrá-lo. Com a análise do desempenho dos alunos, poderá revisar um tópico ou outro, superando eventuais inconsistências (FIELD, 2019).

Esses primeiros passos representam aspectos que têm o potencial de aproximar o aluno de um processo no qual ele visualiza o seu desenvolvimento e recebe motivação para descobrir as suas habilidades e fragilidades. Exatamente esse envolvimento e conexão podem servir para inibir a cola, seja por conta da participação mais direta e interação de todos os atores na avaliação, seja por faltar oportunidade do uso de cola como atalho para aprovação.

Mas, na prática, o que o professor pode adotar como meio eficaz, legítimo e confiável para conciliar com a prova escrita e contribuir para a correção do desvio ético do aluno na avaliação? 
Sugere-se a aplicação de simulação, role-play, aula dialogada, debate, seminário, etc e a partir deles combinar instrumentos que se apresentem adequados à verificação do desenvolvimento dos objetivos do curso. Foram sistematizadas abaixo algumas sugestões de ferramentas de avaliação continuada em relação a trabalhos ou produtos e comportamentos dentro e fora da sala de aula, numa lista não exaustiva e, evidentemente, sujeita a melhoramentos:

A. Exercícios que comparem o desempenho do aluno em momentos diferentes do período letivo. Por exemplo, um no começo, outro no meio e outro no fim do bimestre ou semestre a fim de avaliar a mesma competência e comparar os resultados e implementar a correção da rota (KAFKE; FEFERBAUM, 2020).

B. Diários de bordo: o aluno registra o seu desenvolvimento e as dificuldades enfrentadas durante as aulas ou nas execuções de trabalhos, entregando-os mensalmente para avaliação e conferência da coerência do que foi proposto com o que restou registrado (CENTRO DE ENSINO E PESQUISA EM INOVAÇÃO, 2018). Essa proposta pode apontar como os alunos leem para aulas, quais recursos empregam nos estudos e pesquisas e outras variáveis geralmente indetectáveis no sistema de avaliação tradicional.

C. Trabalhos escritos individualmente ou em equipe: os alunos devem criar uma solução técnica para algum problema apresentado, que pode ser traduzido em redação, julgamento de um caso, pesquisa bibliográfica, relatório de uma experiência envolvendo, por exemplo, como se dá o registro de propriedade por usucapião extrajudicial, entrevistar um promotor de justiça, assistir a uma audiência, acompanhar uma reclamação junto ao órgão administrativo de defesa do consumidor, elaborar uma notificação de despejo, confeccionar um contrato social ou um parecer sobre bitributação etc. Isso envolve o estabelecimento de prazos, a forma de entrega ou apresentação e outros parâmetros. A avaliação deve acompanhar a execução do trabalho por meio de reuniões, relatórios, entregas parciais ou comunicação eletrônica dos alunos com o professor sobre a produção do trabalho. Um cronograma com fases de elaboração pode facilitar o acompanhamento e a atribuição de nota com base no processo e não apenas no produto ou resultado. Nesse caso, criatividade, raciocínio crítico e pontualidade na entrega podem ser pontuados, além da homogeneidade do produto se o trabalho for em grupo (KLAFKE; FEFERBAUM, 2020).

D. Seminário: propor a discussão estruturada de grupo que segue a forma de palestra sobre um tema. Um seminário somente é avaliado formativamente se há efetivo 
acompanhamento do processo, de suas etapas de preparação, do desempenho do trabalho individual e em grupo e não apenas pelo momento da apresentação isoladamente (GHIRARDI, 2012). Sugere-se que o professor acompanhe as etapas de formação do trabalho, podendo fornecer um formulário de avaliação detalhada aos pares, pedindo a cada aluno para responder às perguntas sobre o conteúdo do seminário apresentado e sobre o desempenho do apresentador ou dos apresentadores, a partir do qual haverá um momento para refletir sobre os comentários que cada um deu a seu colega. Em seguida, será dado o feedback dos colegas, a autoavaliação e o feedback individualizado do professor (FIELD, 2019). Esse procedimento pode ser simplificado em classes mais numerosas e de acordo com o tempo disponível para as apresentações.

E. Observação: o professor, monitores ou alunos especialmente designados observam o desempenho dos alunos durante debates, discussões ou simulações em sala de aula. O procedimento exige atenção a cada aluno no seu comportamento e interação com a turma. Nesse caso, o professor observará se o aluno cumpre o objeto da aprendizagem que pode ser, por exemplo, desenvolver capacidade analítica crítica e de trabalho em grupo, se aceita a opinião posta sem questionamentos, se aponta outra perspectiva, se demonstra o domínio esperado sobre o tema, se exerce liderança ou apresenta dificuldade de trabalho em grupo. A avaliação será conduzida com registro das observações por escrito, checklist, relatório ou simples anotações, para facilitar a atribuição de nota e servir de comprovação das razões adotadas (KLAFKE; FEFERBAUM, 2020).

Conduzir a observação para todos os alunos da turma pode ser tarefa executável apenas com o auxílio de terceiros (monitores, auxiliares, alunos designados para esta função) e pode ser melhor empregada se associada à autoavaliação e avaliação por pares, podendo ser destacado um aluno em cada grupo como responsável por apresentar um relatório de observação do que foi feito durante a proposta da aula ou trabalho.

Na hipótese, indicadores comuns que podem ser usados na avaliação são "presença nas aulas, quantidade de falas, qualidade das falas, relacionamento com colegas, atuação no grupo, utilização de preparação prévia, cooperação com o grupo, seriedade, engajamento com o tema da aula" (KLAFKE; FEFERBAUM, 2020, p. 273).

F. Perguntas entre alunos: possibilitar que alunos façam perguntas a colegas sobre leituras indicadas na aula anterior para a aula subsequente, como aprendizado colaborativo. 
Assim, o professor acompanhará as perguntas e as respostas apresentadas, a seriedade com que perguntas e respostas são formuladas e indicará a correção ou não delas.

G. Exposição de uma questão de múltipla escolha para a turma: expor uma questão de múltipla escolha para toda a turma, contemplando um problema a ser solucionado, com uma ou mais opções de respostas corretas e respostas erradas. Todos os alunos poderão votar, anonimamente através de urna com votação em papel ou através de aplicativos eletrônicos. A partir do resultado, o professor pode convidar alunos para defender e explicar uma outra resposta e o motivo de tê-la escolhido. Pode ser incluída entre as alternativas a resposta "não sei" e isso informará ao professor eventuais deficiências de como o conteúdo foi discutido ou apresentado e o grau de apreensão do conhecimento pela turma e indicará necessidade de revisão para o professor ou de maior investimento no estudo para o aluno. É recomendável que o professor incentive os alunos que optaram pela resposta "não sei" a conversar com um ou dois colegas por alguns minutos e em seguida votar novamente. Por fim, o professor deverá explicar porque cada alternativa está correta ou errada (FIELD, 2019).

H. Empregar ferramentas tecnológicas: o uso de ferramentas tecnológicas para o momento da avaliação através de podcasts, sites, vídeos e aplicativos a serem utilizados de forma síncrona para fazer brainstorm, enquetes, respostas simultâneas pela turma, quadros interativos etc $^{8}$ tem o condão de aumentar o engajamento do aluno e possibilitar uma avaliação sobre a forma e a qualidade da participação dos alunos.

I. Questionários autoavaliativos: apresentação de quesitos a serem respondidos pelos alunos sobre como veem o próprio desempenho. "Qual a coisa mais importante que você aprendeu durante esta aula?”; “que dúvida permanece sem resposta?”; “dentre as atividades propostas, se você não teve um desempenho tão bom quanto gostaria, quais etapas você poderia melhorar para o futuro aprendizado?". A prática exige que os alunos sejam bem orientados sobre o propósito da avaliação para, na sua ótica, indicar os pontos positivos e negativos. O questionário pode ser empregado como avaliação de revisão, no qual o aluno é solicitado a se envolver numa revisão dirigida e ao fim apresentar um plano de melhoria (KLAFKE; FEFERBAUM, 2020).

J. Reescrita: estratégia que exige que o aluno reescreva o trabalho ou atividade que precisa de melhorias depois do feedback do professor, por exemplo, indicando dois pontos

8 Nos endereços eletrônicos indicados a seguir podem ser encontradas variadas opções de uso gratuito e para inspiração: https://jamboard.google.com, https://www.sessionlab.com/library, https://awwapp.com, https://quickdraw.withgoogle.com, www.menti.com, www.kahoot.it, www.slack.com, www.padlet.com. 
fortes em sua tarefa e duas fragilidades e maneiras pelas quais pode melhorar tais pontos no futuro (FIELD, 2019).

Obviamente que as sugestões podem ser expandidas para outras práticas pelo professor e que, a depender das peculiaridades de cada um, podem ocorrer em atividades, trabalhos e aulas, de modo autoexecutável, orientado pelo professor e/ou com a participação dos pares. Pode, ainda, haver avaliação analítica ou holística ${ }^{9}$.

Existem, é claro, diversas técnicas de avaliação formativa e estratégias eficazes além das apresentadas acima e os leitores deste artigo podem ter implementado técnicas adicionais mais exitosas em suas salas de aula. A única intenção do elenco apresentado é o estímulo para a sua implementação.

Ao longo de um curso, o professor pode ver o que funciona e o que não funciona de acordo com o perfil da turma, descobrindo o que envolve ou não os alunos. O importante é que, com cada reflexão, seja possível criar as estratégias para determinar quais novas avaliações formativas são desejáveis e adicioná-las ao processo de ensino e aprendizagem, tornando-as mais eficazes.

\section{CONSIDERAÇÕES FINAIS}

A cola deve passar a ser considerada pelos atores do processo educacional como um problema ético na conduta dos alunos, mesmo no ensino superior, dadas as consequências não apenas para aprendizagem, mas também para a sociedade, que espera um profissional devidamente formado técnica e eticamente e apto a desempenhar com destreza as responsabilidades das suas funções.

A preocupação com a cola, mesmo fora da academia, já revelou a relevância do tema, inclusive, quando da criminalização da cola em concursos e seleções públicas (art. 311-A do Código Penal).

A solução para o problema da cola passa por questões culturais e por múltiplos fatores que exigem enfrentamento multidimensional, sendo uma dessas dimensões a questão da avaliação, que não pode ser vista como uma oportunidade para prática da cola.

A partir dessa constatação, propôs-se repensar a forma de avaliação e as vantagens de conciliar a avaliação tradicional e certificatória nos cursos de direito, por meio de provas, com

9 A avaliação analítica separa os diversos critérios avaliados por item e atribui nota a cada um dos itens. A avaliação holística não desmembra os critérios e atribui uma nota geral equalizando nota com o alcance do objetivo da aprendizagem (KLAFKE; FEFERBAUM, 2020). 
a avaliação formativa, que compreende avaliar o processo de aprendizagem em diversos pontos ao longo da extensão do curso e fornecer feedback para melhorar o aprendizado do aluno.

Repise-se que a avaliação formativa, entretanto, não é apenas o fornecimento de feedback, embora envolva necessariamente o feedback para melhorar a aprendizagem do aluno, ao dar informações concretas sobre o que aprenderam ou não.

A ideia não é nova. Por exemplo, nos esportes oficiais, onde o dopping é proibido e refutado, é comum que os atletas monitorem o seu desempenho durante a preparação para competições e exibições, a fim de corrigir rumos e assegurar a aptidão necessária ao êxito das provas. Analogicamente, no ensino-aprendizagem a avaliação continuada, formativa, servirá para o aluno monitorar o grau de aprendizagem, corrigindo qualquer mal-entendido, preenchendo lacunas, através da reflexão, da prudência e da visão crítica sobre o desenvolvimento do seu conhecimento e aplicação prática. Nesse cenário, a cola, semelhante ao dopping, é indesejada para que o resultado almejado seja efetivo e justo.

Ao criar condições para que o aluno reflita (“qual parte disso eu já sei?", "estou entendendo esse conceito?”, “o que faltou para eu atender ao resultado esperado?”, "por que errei?”, “como posso melhorar?”), a avaliação formativa implanta valores e noções de ética e justiça, para que o aluno encare a avaliação e as notas como um processo natural e complementar e não como um momento decisivo do seu destino, onde vale a regra do tudo ou nada.

Ainda que a perspectiva certificatória permaneça necessária para que o aluno encontre na universidade tipos de avaliações semelhantes às que lhe serão exigidas por ocasião da conclusão do curso ou após a formatura, com os exames que lhe serão impostos para o exercício das profissões jurídicas, a adoção concomitante de avaliações formativas que tenham espaço privilegiado na composição de suas notas poderá alterar o cenário constatado em pesquisas que indicam certa predisposição para a cola por parte da maioria dos alunos.

As práticas sugeridas neste trabalho demonstram como estreitar a relação do aluno com a avaliação, por meio das diversas oportunidades para obtenção de notas e, consequentemente, de chances de melhoria do seu desempenho e de aprovação, desestimulando os desejos de trapacear por tornar a cola praticamente inócua.

\section{REFERÊNCIAS}

Revista de Pesquisa e Educação Jurídica | e-ISSN: 2525-9636 | Encontro Virtual | v. 7 | n. 2 |

p. $21-41$ | Jul/Dez. 2021. 
BARBOSA, Evandro Brandão. "Cola" em sala de aula: a taxonomia é o antídoto. Revista Atlante: Cuadernos de Educación y Desarrollo (julio 2013). Disponível em https://www.eumed.net/rev/atlante/2013/07/cola-sala-aula.html. Acesso em 15 dez. 2020.

BARBOSA, Lívia. O jeitinho brasileiro: a arte de ser mais igual do que os outros. Rio de Janeiro: Elsevier, 2005.

CALLAHAN, David. The cheating culture: why more americans are doing wrong to get ahead. Boston: Harcourt, 2004

CENTRO DE ENSINO E PESQUISA EM INOVAÇÃO (CEPI). O futuro das profissões jurídicas: você está preparad@? Sumário executivo da pesquisa qualitativa "tecnologia, profissões e ensino jurídico". FGV DIREITO SP, São Paulo, 2018. Disponível em https://direitosp.fgv.br/sites/direitosp.fgv.br/files/arquivos/cepi_futuro_profissoes_juridicas_q uali_v4.pdf. Acesso em 17 ago. 2020.

COSTA, Lorena Martins; PIMENTA, Maria Alzira. Um estudo sobre a prática da fraude acadêmica em quatro continentes. Revista Multitemas, Campo Grande, n.47, p. 109-128, jan/jun. 2015. Disponível em https://www.multitemas.ucdb.br/multitemas/article/view/186/1223. Acesso em 15 dez. 2020.

FIELD, Heather M., A Tax Professor's Guide to Formative Assessment (15 de maio de 2019). 22 Florida Tax Review 363 (2019), UC Hastings Research Paper No. 356, Disponível em https://ssrn.com/abstract=3388943. Acesso em 15 dez. 2020.

FRIEDLAND, Steven, Rescuing Pluto from the cold: creating an assessment-centered legal education (August 15, 2017). Disponível em https://ssrn.com/abstract=3019431. Acesso em em 01 de. 2020.

GHIRARDI, Garcez. O instante do encontro: questões fundamentais para o ensino jurídico. São Paulo: Fundação Getúlio Vargas, 2012.

KLAFKE, Guilherme Forma; FEFERBAUM, Marina. Metodologias ativas em direito: guia prático para o ensino participativo e inovador. São Paulo: Atlas, 2020.

PERRENOUD, Philippe. Dez novas competências para ensinar. Trad Patrícia Chittoni Ramos. Porto Alegre: Artes Médicas Sul, 2000.

PIMENTA, Maria Alzira de Almeida; DOMINGUES, Ivo; VIEIRA, Thereza Carolina Gonçalves. A fraude acadêmica e o código de conduta na universidade: a responsabilidade da formação ética. Revista Educação em Questão, Natal, v. 57. n.54, p. 1-23, e-18656, ou./dez. 2019. Disponível em https://periodicos.ufrn.br/educacaoemquestao/issue/view/918. Acesso em 01 de. 2020.

PIMENTA, Maria Alzira de Almeida; PIMENTA, Sônia de Almeida. Fraude acadêmica: estudo comparativo entre o Nordeste e o Sudeste do Brasil. Série-Estudos - Periódico do Programa de Pós-Graduação em Educação da UCDB, Campo Grande, n.39, p. 213-230, 
já./jun. 2015. Disponível em https://www.serie-estudos.ucdb.br/serie-estudos/article/view/819. Acesso em 20 dez. 2020.

PIMENTA, Maria Alzira de Almeida; PIMENTA, Sônia de Almeida. Fraude em avaliações no ensino superior do Brasil: aproximações com uma pesquisa de Portugal. Avaliações

(Campinas), Sorocaba-SP, v. 21, n. 3, p. 953-974, nov. 2016. Disponível em

http://www.scielo.br/scielo.php?script=sci_arttext\&pid=S1414-

$40772016000300953 \& \operatorname{lng}=$ en\&nrm=iso. Acesso em 20 dez. 2020.

VELUDO-DE-OLIVEIRA, Tânia Modesto; AGUIAR, Fernando Henrique Oliveira;

QUEIROZ, Josimeire Pessoa de; BARRICHELO, Alcides.Cola, plágio e outras práticas

acadêmicas desonestas: um estudo quantitativo-descritivo sobre o comportamento de alunos de graduação e pós-graduação na área de negócios. Revista de Administração Mackenzie, São Paulo, v. 15, n.1, p. 73-97, jan/fev. 2014. Disponível em

http://www.scielo.br/scielo.php?script=sci_arttext\&pid=S1678-

69712014000100004\&lng=en\&nrm=iso. Acesso em 15 dez. 2020. 